\title{
Trauma, alcohol and drugs misuse in car and motorcycle drivers: a prevalence study in a level one trauma center
}

\author{
Federica Renzi ${ }^{1} \cdot$ Elisa Reitano $^{2} \cdot$ Davanzo Franca $^{3} \cdot$ Osvaldo Chiara $^{4}\left(\mathbb{D} \cdot\right.$ Stefania Cimbanassi ${ }^{1}$
}

Received: 21 April 2021 / Accepted: 9 July 2021 / Published online: 13 September 2021

(c) The Author(s) 2021

\begin{abstract}
Alcohol and drugs misuse represents an important social problem. There is no agreement about influence of ethanol and drugs on trauma severity and clinical course. The aim of this study was to investigate the impact of alcohol and drugs abuse on road related trauma managed to our Level I Trauma Center. Data of 1067 car or motorcycle drivers consecutively admitted in a 5 years period were retrospectively analyzed. The sample was divided into two groups: patients with alcohol and/or drugs misuse and patients without detectable plasmatic levels or not screened because no clinical suspicion of these substance. Demographic data, mechanism of trauma, severity of injury, daily and season time of trauma distribution, alcohol and drugs levels and outcomes were retrieved. Alcohol or drugs misuse were detected in 242 patients. Heavy alcohols levels were the $62.3 \%$. Among drugs cannabis was the most detected substance. These patients were significantly younger than the overall study population $(p=0.011)$, with a higher ISS $(p=0.012)$ a lower RTS $(p=0.047)$, a lower GCS $(p=0.005)$ and an higher head injuries severity $(p=0.030)$. Regarding time distribution, Saturday was the day with the highest percentage of trauma associated with substance misuse (21\%). Alcohol/drugs misuse plays a very important role in the epidemiology of road related trauma. Despite the higher severity of trauma scores and the higher incidence of severe head injuries in patients with alcohol or drugs consumption, there were no effects of this substances on mortality of injured patients involved in road crashes.
\end{abstract}

Keywords Trauma $\cdot$ Alcohol $\cdot$ Drugs $\cdot$ Trauma center

\section{Introduction}

Road accidents play an important role in public health [1]. According to the latest report of the World Health Organization (WHO) [2], about 1.25 million people die each year as a result of road accidents, and people involved in non-mortal

Osvaldo Chiara

osvaldo.chiara@unimi.it

1 General Surgery and Trauma Team, ASST Niguarda, Piazza Ospedale Maggiore 3Milano, 20162 Milan, Italy

2 Division of General Surgery, Department of Translational Medicine, Maggiore Della Carità Hospital, University of Eastern Piedmont, Corso Giuseppe Mazzini 18, Novara, Italy

3 Milan Poison Control Centre, ASST Grande Ospedale Metropolitano Niguarda, Piazza dell'Ospedale Maggiore 3, 20162 Milan, Italy

4 General Surgery and Trauma Team, University of Milan, ASST Niguarda, Piazza Ospedale Maggiore 3Milano, 20162 Milan, Italy crashes are between 20 and 50 million. Among road accident risk factors, alcohol and illicit drugs use, seems to be increasingly dominant, [3]. As shown by WHO's report about global status of road safety [2], only 34 countries have drink-driving laws in line with the best practice. Among these countries, 21 are in the European Region.

The interactions of alcohol and drugs on the driving skills are well known and proven. Alcohol affects the neuropsychic functions, interacting with sensory-motor and behavioral functions resulting in alterations of visual perception, reaction times, ability to concentration and judgment [4-6]. The neurotoxic action of drugs leads to stimulation effects, depression, hallucinatory phenomena, and consequent impairment of driving performance [3].

Different epidemiological studies demonstrated that alcohol misuse, reducing driving performance, increased risk of road accidents [7, 8]. However, there is low evidence of the association of drugs abuse and road accidents [3, 9] and literature is conflicting. Different authors agree on the association of alcohol and illicit drugs misuse with an increased need of Intensive Care Unit (ICU) [10-12] and 
with a higher morbidity, while no associations were found with the Glasgow Coma Scale (GCS) level, hospital length of stay (LOS), mortality rate [11], sepsis or multi-organ failure (MOF), [13]. Different studies demonstrated no associations between the alcohol or drugs misuse and the severity of trauma, estimated with the Abbreviated Injury Scale (AIS) and the Injury Severity Score (ISS) [11, 12, 14]; However, other studies supported the relationship between alcohol/ drugs misuse and trauma severity [15-17]. The aim of this study is to provide an epidemiological description of alcohol and drugs use in drivers and to investigate the impact on the injury severity, comparing patients who used one or more substances with patients who did not.

\section{Methods}

All data on car and motorcycle-related trauma consecutively admitted to the Niguarda Trauma Center from January 2011 to December 2015 were retrieved from our Trauma Registry. This study was conducted in conformity to the principles declared to the National Commission for Data Protection and Liberties (CNIL: 2210699) and in accordance with the ethical principles described in the Declaration of Helsinki. Demographic data, mechanism of trauma, type of vehicle, Abbreviated Injury Scale (AIS), Injury Severity Scale (ISS), daily, seasons time and outcome were retrospectively analyzed. The Italian law provides for the possibility of verifying the level of illicit substances in the blood or urine of drivers only (a) at the request of the police or (b) due to the clinical suspicion by the doctor. In the second condition, informed consent should be obtained from conscious patients.

Plasmatic levels cut-off of illicit substances were [18]: $\geq 50 \mathrm{mg} / \mathrm{dl}$ of alcohol; $\geq 300 \mathrm{ng} / \mathrm{mL}$ of benzodiazepines, $\geq 300 \mathrm{ng} / \mathrm{mL}$ of urinary metabolites of cocaine $\geq 300 \mathrm{ng} / \mathrm{dL}$ of opiates and $\geq 50 \mathrm{ng} / \mathrm{mL}$ of delta9-tetrahydrocannabinol (THC) (cut-off $>50 \mathrm{ng} / \mathrm{mL}$ ).

According with toxicological analysis results, patients were identified as:

- Patients who used one or more substances (Group 1); - Patients with no detected substance or not screened for drugs use (Group 2);

- Patients with high blood levels of opiates and/or benzodiazepines, with documented administration of these substances by pre-hospital health care personnel were included in the Group 2.

In the Emergency Department the trauma leader decided to carry out toxicological exams in subjects with behavioral modifications or altered physical exam or vital signs suggesting alcohol or drugs abuse, such as alcohol smell of breath, ocular signs (miosis), tachycardia, hyper or hypotension, widespread tremors, obtunded consciousness. Sample was further divided in two groups: patients with an ISS lower or greater than 25 , in order to assess the trauma severity in accordance to substance misuse. Injuries were grouped by anatomical region: head, chest, abdomen, and extremities according to AIS classification. Five age groups were considered ( $\leq 17$ years, $18-29$ years; $30-35$ years; $36-50$ years and $>50$ years) to describe the epidemiological distribution of substance misuse. Finally, differences among car and motorcycle drivers were analyzed to investigate differences on trauma severity and outcome between them.

Data were recorded in a computerized spreadsheet (Microsoft Excel 2016; Microsoft Corporation, Redmond; WA) and analyzed with statistical software (IBM Corp., released 2012, IBM SPSS Statistics for Windows, Version 21.0; Armonk, NY, IBM Corp.). Kruskal-Wallis test was used to compare continue variables while categorical variables were compared using Pearson's Chi-squared test. Two different multivariate models were performed: the first to identify drugs or alcohol correlation with the injury's severity and patient's demographic data; the second to identify any possible correlation between the injury severity and the type of vehicle (car vs motorcycle drivers). Variables with a $P$ value below 0.05 at the bivariate analysis were considered statistically significant and were included in the logistic regression model.

\section{Results}

During the study period, 2811 trauma patients involved in road traffic related accidents, were admitted to our Trauma Center. Car and motorcycle drivers who fulfilled the inclusion criteria were 1067 . The mean age of the study population was 44 years (10-92 years) and 925 (86.7\%) were male. The overall mortality was $3.3 \%$.

Subjects with positive toxicological analyses (group 1) were 242 (car drivers 91, 37.6\%; motorcycle drivers 151, 62.4\%). Group 2 patients were 825: 164 (31.7\%) car drivers and 354 (68.3\%) motorcycle drivers.

Patients with heavy alcohol consumption accounted for $62.3 \%$. Cannabis was the most detected drug (39.3\%), followed by cocaine $(27.3 \%)$, opiates $(1.7 \%)$ and benzodiazepines (1.2\%).

Motorcycle drivers were found to be more frequently positive for drugs misuse than car drivers $(p=0.104)$. General characteristics of the two groups are resumed in Table 1 . Logistic regression model showed no correlation between drugs/alcohol misuse and trauma severity with the exception of a higher injury severity (Head AIS) in Group1.

Sixty-two patients of group $1(25.6 \%)$ were found to be positive for the contemporary use of different substances 
Table 1 Demographic data between the groups

\begin{tabular}{lccc}
\hline & Group 1 & Group 2 & $P$ value \\
\hline Male $n(\%)$ & 242 & 825 & \\
Age median (IQR) & $219(90.5)$ & $706(85.6)$ & $0.048^{*}$ \\
Car drivers $n(\%)$ & $42(33.75-51)$ & $45(34.50-55.0)$ & $0.011^{*}$ \\
Motorcycle drivers $n(\%)$ & $91(37.6)$ & $264(32)$ & 0.104 \\
GCS median (IQR) & $151(62.4)$ & $561(68)$ & 0.104 \\
RTS median (IQR) & $15(14-15)$ & $15(15-15)$ & $0.005^{*}$ \\
ISS median (IQR) & $12(11-12)$ & $12(12-12)$ & $0.047^{*}$ \\
Death probability median (IQR) & $11(5-21)$ & $9(4-21)$ & $0.012^{*}$ \\
Dead $n(\%)$ & $0.80(0.4-3.0)$ & $0.60(0.40-3.0)$ & 0.096 \\
Head AIS $\geq 3 n(\%)$ & $7(2.9)$ & $28(3.4)$ & 0.700 \\
Chest AIS $\geq 3 n(\%)$ & $57(38)$ & $140(28.6)$ & $0.030^{*}$ \\
Abdomen AIS $\geq 3 n(\%)$ & $82(83.7)$ & $247(81.5)$ & 0.629 \\
Extremity AIS $\geq 3 n(\%)$ & $23(43.4)$ & $163(37.6)$ & 0.873 \\
\hline
\end{tabular}

GCS Glasgow Coma Scale, RTS Revised Trauma Score, ISS Injury Severity Score, AIS Abbreviated Injury Scale

*Statistical significance

(Multi-drugs association-MDA). Between the MDA, the association cocaine-alcohol was the most detected (32 patients, $13.2 \%)$, followed by the association cannabisalcohol (31 patients, 12.8\%). However, patients were often positive for more MDA: Cocaine-alcohol-cannabis association was the most detected (14 patients, 5.8\%). Analyzing the MDA in relation to the type of vehicle, MDA was more associated with motorcycle drivers $(p=0-041)$.

Patients with substance abuse were significantly younger than the overall study population (42 years, IQR $33.75-51.00$ vs 45 years, IQR 34.50-55; $p=0.011$ ), with an higher ISS (11, IQR 5-21 vs 9 IQR 4-21; $p=0.012)$ and an higher although not significant death probability $(0.80$ IQR $0.40-3.0$ vs 0.60 , IQR $0.40-3.0 ; p=0.096)$. Moreover group 1 patients showed a lower GCS $(p=0.005)$ and RTS $(p=0.047)$. Injuries with head AIS $\geq 3$ were found to be more frequent in group $1(p=0.030)$, while no difference was found between the AIS of the remaining body districts (Table 1).

Injuries with $\mathrm{AIS} \geq 3$ in at least one body region were found in $544(51.0 \%)$ of which 138 patients in group 1 (57\%): 94 motorcycle drivers $(62.3 \%)$ and 44 car drivers $(48.4 \%), p=0.034$. In group 2 injuries with $\mathrm{AIS} \geq 3$ in at least one body region were found in 406 patients (49.2\%): 308 motorcycle drivers (54.9\%) and 98 car drivers $(37.1 \%), p \leq 0.001$. A significant overall difference was found between the two groups $(p=0.03)$.

In group 1 patients after a peak in the early hours of the day (00AM-06AM) the number of crashes decreases, then increasing again, with a variable progression after noon (Fig. 1). Alcohol and drugs misuse was most frequent on Saturday (21\%), followed by Sunday (18.3\%) and Thursday $(15.9 \%)$.
Fig. 1 Daily distribution of substance misuse in trauma (Green line: GROUP 1; Blue line: GROUP 1 and 2)

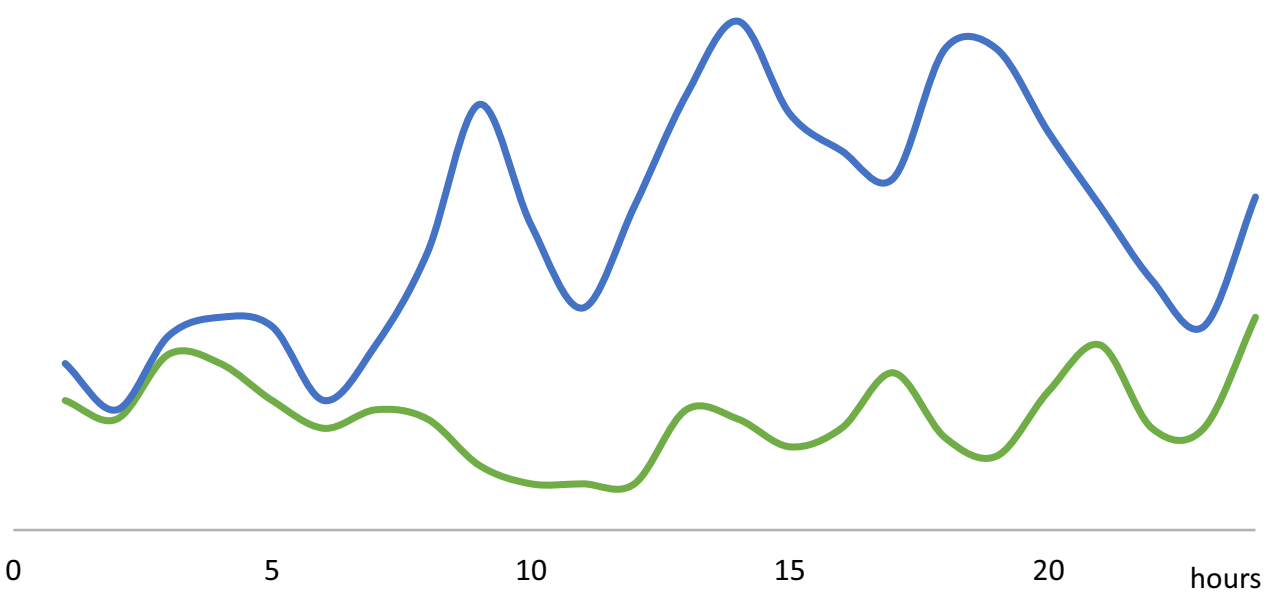


Thirty-five patients died: 15 car drivers and 20 motorcycle drivers. They were mainly male (94.3\%) and significantly older than survived patients (median 55 years, IQR 39-63 vs. 44 years, IQR $34-54 ; p=0.004$ ). Seven patients among them were found to be positive at toxicological analyses. Dead patients showed a lower GCS (median 3, IQR 3-3 vs median 15, IQR 15-15; $p \leq 0.001$ ), a higher ISS (median 45, IQR 37-75 vs median 9, IQR 5-19; $p \leq 0.001$ ) and a higher RTS (median 2, IQR 2-4 vs median 12, IQR 12-12, $p \leq 0.001$ ) if compared with survived patients. The rate of deaths was not significantly different between group 1 and 2 (Table 1). There was no difference for positivity of alcohol or drugs misuse in patients with an ISS lower or greater than 25 (Table 2). In Table 3 the distribution of substance misuse in different age groups is described: differences between the age groups were statistically significant for alcohol and cannabis misuse, with the age group between 36 and 50 years old more often positive at the screening tests. This age group was found to be more often positive also for cocaine, opiates and benzodiazepine misuse, even if no statistical difference between the other age groups was showed. Table 4 showed comparison among car and motorcycle drivers: no differences were showed in terms of drugs misuse between the groups. Multivariate logistic regression showed no
Table 2 ISS in patients with alcohol or drugs misuse

\begin{tabular}{lcccc}
\hline Substances & $\begin{array}{l}\text { Patients positive for sub- } \\
\text { stance misuse }\end{array}$ & ISS $<25$ & ISS $\geq 25$ & $P$ value \\
\hline Ethanol $n(\%)$ & $151(14.2)$ & $121(80.1)$ & $30(19.9)$ & 0.732 \\
Cocaine $n(\%)$ & $66(6.2)$ & $47(71.2)$ & $19(28.8)$ & 0.105 \\
Opiates $n(\%)$ & $4(0.4)$ & $3(75)$ & $1(25 \%)$ & 0.841 \\
Cannabis $n(\%)$ & $95(8.9)$ & $7(80)$ & $19(20)$ & 0.817 \\
Benzodiazepine $n(\%)$ & $3(0.3)$ & $1(33.3)$ & $2(66.7 \%)$ & 0.051 \\
\hline
\end{tabular}

*ISS Injury Severity Score
Table 3 Substance misuse by age groups

\begin{tabular}{llllccc}
\hline Substances & $\leq 17$ years & $18-29$ years & $30-35$ years & $36-50$ years & $\geq 50$ years & $P$ value \\
\hline Ethanol $n(\%)$ & 0 & $10(6.6)$ & $35(23.2)$ & $65(43)$ & $41(27.2)$ & $0.003^{*}$ \\
Cocaine $n(\%)$ & 0 & $3(4.5)$ & $17(25.8)$ & $26(39.4)$ & $20(30.3)$ & 0.103 \\
Opiates $n(\%)$ & 0 & 0 & $1(25)$ & $2(50)$ & $1(25)$ & 0.905 \\
Cannabis $n(\%)$ & 0 & $9(9.5)$ & $27(28.4)$ & $39(41.1)$ & $20(21.1)$ & $0.002^{*}$ \\
Benzodiazepine $n(\%)$ & 0 & 0 & 0 & $1(33.3)$ & $2(66.7)$ & 0.809 \\
\hline
\end{tabular}

*Statistical significance

Table 4 Differences between car and motorcycle drivers

\begin{tabular}{|c|c|c|c|c|}
\hline & Car drivers 355 & Motorcycle drivers 712 & $P$ value & $\begin{array}{l}P \text { value Logistic regres- } \\
\text { sion }(95 \% \mathrm{CI})\end{array}$ \\
\hline Male $n(\%)$ & $258(24.2)$ & $667(62.5)$ & $\leq 0.001^{*}$ & $\leq 0.001 *(5.71-71.28)$ \\
\hline Age median (IQR) & $43(34-56)$ & $44(34.25-54)$ & 0.728 & \\
\hline Drugs/alcohol abuse $n(\%)$ & $91(37.6)$ & $151(62.4)$ & 0.104 & \\
\hline GCS median (IQR) & $15(15-15)$ & $15(15-15)$ & 0.625 & \\
\hline RTS median (IQR) & $12(12-12)$ & $12(12-12)$ & 0.140 & \\
\hline ISS median (IQR) & $5.5(2-17)$ & $10(5-22)$ & $\leq 0.001^{*}$ & $0.661(0.97-1-03)$ \\
\hline Death probability median (IQR) & $0.60(0.3-2.5)$ & $0.80(0.40-3.0)$ & $\leq 0.001^{*}$ & $0.029 *(0.97-0.99)$ \\
\hline Dead $n(\%)$ & $15(1.4)$ & $20(1.9)$ & 0.221 & \\
\hline Head AIS $\geq 3 n(\%)$ & $55(8.6)$ & $142(22.2)$ & $0.021^{*}$ & $0.054(0.98-3.97)$ \\
\hline Chest AIS $\geq 3 n(\%)$ & $97(24.2)$ & $232(57.9)$ & $0.044 *$ & $0.182(0.78-3.54)$ \\
\hline Abdomen AIS $\geq 3 n(\%)$ & $32(13.4)$ & $69(29)$ & 0.866 & \\
\hline Extremity AIS $\geq 3 n(\%)$ & $46(8.1)$ & $168(29.6)$ & 0.867 & \\
\hline
\end{tabular}

GCS Glasgow Coma Scale, RTS Revised Trauma Score, ISS Injury Severity Score, AIS Abbreviated Injury Scale, CI confidence interval

*Statistical significance 
differences in terms of injury severity in the different body areas, while a positive correlation was found between the ISS level and the motorcycle drivers.

\section{Discussion}

Alcohol and/or drug misuse plays a very important role in the epidemiology of road related trauma. The effects of these substances on neuropsychic and motor functions result in a reduction of driving performance, increasing the risk of accidents [19-21]. A detailed profile of these trauma patients is complex to draw, representing an extremely heterogeneous population with different involved variables, such as $[22$, 23]:

- Psycho-physical features of patients (age, comorbidities, metabolism);

- Environment, socio-cultural habits and lifestyle influencing accessibility and availability of drugs and affecting the type of abuse and the frequency of assumption (dependence VS occasional consumers);

- Road safety (road conditions, visibility), respect of the Road Code and vehicle type (use of seat belts, car equipped with airbags).

In our study, the $22.68 \%$ of the drivers of vehicles showed to be positive for alcohol or drugs misuse, despite the drink and drugs-driving laws.

Different authors [24, 25] investigated the epidemiological distribution by age on alcohol and drugs misuse on road traffic injuries in other countries. In line with these results, our analysis showed that drugs and alcohol misuse are more frequent in male of middle age (36-50 years). The highest number of crashes occurred at night and early in the morning, mostly on Saturday and Sunday, classically associated with increased social events and moments of aggregation. The high frequency of road accidents on Thursdays could be related to the latest social habits in Milan. In the last years, in fact, there was an increase in social events right on this day of the week. Demographic features of patients in Group 1 , as well as the temporal distribution of road crashes, could be related with binge drinking $[8,26,27]$. This phenomenon is characterized by the assumption of a high amount of alcohol in a short time, mainly in the weekend or during parties.

Alcohol was the most common misuse substance (62.4\%), regardless of age, sex, and type of vehicle used. Among drugs, cannabis was the most common (39.3\%). This widespread use of alcohol and cannabis was likely to be explained in their greater affordability and easy of purchase compared to other drugs, enabling more extensive use not only among young people, who reasonably have more limited economic availability, but also in the middle age.
According to the literature [11, 14, 22], the comparison between group 1 and group 2 showed differences on the severity of the injuries. Patients in group 1 were younger, with a higher ISS, a lower GCS and RTS and a higher Head AIS. However, logistic regression model showed no correlation between drugs/alcohol misuse and trauma severity, with the exception of head injuries (Table 1).

In car drivers' group, safety devices such as seat belts and airbags probably prevented the direct impact of the chest on steering wheel, dashboard and windscreen. Therefore, the lower GCS on group 1 could be partially due to the sedative effects of drugs or alcohol misuses, but also imputable to an increased trauma severity as a result of substance consumption.

Despite the higher recurrence of at least one AIS $\geq 3$ injury in each body regions in group 1 , no correlation between ISS and substance misuse was observed (Table 2).

Multi-drugs abuse (MDA) was documented in $25.6 \%$ of patients of group 1 , mostly motorcyclists. In contrast with literature, the most common MDA association was alcohol and cocaine, instead of alcohol and cannabis [28]. The concomitant use of these two substances is proved to be dangerous, as their mixture leads to the formation of Coca-ethylene (CE); an active metabolite that acts on the central nervous system, increasing dopaminergic activity, with euphoric effect [29]. CE is slowly metabolized by the cerebral cortex and this prolongs the duration of the effects [10]. CE activity is burdened by an important cardiotoxic action leading to arrhythmias, electrocardiographic alterations, reduced cardiac contractility, increased risk of heart disease and increased blood pressure $[29,30]$. CE plays a key role during the evaluation of patient hemodynamic, because it could be responsible of some cardio-circulatory alterations that cannot be explained by the injuries found after crash [10].

According to literature [11], there was no significant effect on mortality of alcohol and/or drugs on injured patients involved in road crashes. Our study suggested, however, an overall higher severity in patients with drug misuse, as demonstrated by the higher ISS and the lower GCS and RTS of group 1, although logistic regression model showed only a positive correlation with a higher Head AIS. Indeed, epidemiologic limit of this analysis was the lack of information on drugs abuse in patients directly dead on the scene (not evaluated in a hospital). Different studies [31, 32], based on toxicological analysis performed on the drivers dead on the road evidenced that alcohol was the most commonly detected substance. Therefore, further studies are needed to confirm the impact of alcohol and drugs on mortality. As showed in Table 4, no differences were found in terms of drugs and alcohol misuse between car and motorcycle drivers. However, logistic regression model showed a higher death probability in motorcycle drivers, although no differences were found in terms of mortality between the groups. 
The WHO Global Status Report on Road Safety 2015 [2], highlights that in Italy road traffic death involving alcohol were about $25 \%$. This was a high percentage if compared with other European countries (Germany Austria, Ireland, Switzerland, Denmark, Czech Republic, Russia) and no European countries such as China and Brazil where alcohol-related deaths were less than $10 \%$. Worst results were reported in France (29\%), Portugal (31\%), Australia (30\%), New Zealand (31\%), Canada (34\%) and United States $(31 \%$, with higher legal limits: $0.8 \mathrm{mg} / \mathrm{dL})$.

According to WHO Global Status Report on Road Safety 2018 [33], Italy is one of the countries with an overall best practice for drink-driving laws. However, our study showed how current social measures should be improved to avoid road related trauma linked to alcohol and drugs misuse.

This study presented several limitations. Not all drivers involved in road crashes and managed by our Trauma Team were subjected to toxicological analysis. As previously described, the decision to perform these exams was carried out by the Trauma Leader in relation to a clinical suspect. Toxicological analyses performed in all patients could lead to more objective data. However, only few patients with normal vital signs, mostly affected by minor trauma, were not tested because any abuse of prohibited substance was unlikely.

An additional limitation applies the type of analysis performed for drugs. The evaluation of urinary metabolites of cocaine, opiates and cannabis does not provide information about a recent abuse of these drugs, but only a previous use. These metabolites have different elimination times: 15-30 days for cannabis, 2-4 days for cocaine and opiates [18]. The elimination rate depends by a lot of factors such as the metabolism and hydration status of each patient, the tolerance to the substance of abuse, the frequency of use and the amount of drug dose [29]. Having plasmatic levels of these drugs, as for alcohol and benzodiazepines, even if more expensive, would provide more reliable results, both for clinical practice and for prospective studies.

There are, moreover, non-investigated but widely used psychoactive substances, such as ecstasy or MDMA (3,4-methylenedioxy-methane-methane) and "Smart Drugs". The latter category of substances consists of natural and/or synthetic substances that promote the release of neurotransmitters and act as inducers of neuronal growth, improving cognitive capabilities and concentration. Alongside these "positive effects", negative effects such as induction of addiction, hallucinations, seizures and psychosis are reported, [34]. The main feature of these products is to be subject to free sale because they have not yet been legally recognized as illicit drugs.

In conclusion, in this study alcohol was the most widespread substance, however, the use of drugs among drivers involved in road accidents was far from negligible and often associated with concomitant alcohol intake, thus resulting in a synergistic effect of these illicit substances. These patients showed an overall higher severity and a positive correlation with a higher head AIS, but no single substance was found to be associated with the cluster of high severity (ISS $\geq 25$ ) injuries. Finally, alcohol and drugs misuse represent an important social problem. Clarify the epidemiological distribution of this phenomena could be crucial to enhancing prevention measures and reducing the related morbidity, with a social cost benefit.

Further epidemiological studies are needed to expand the study sample, possibly considering other hemodynamic and metabolic parameters in order to obtain more complete information.

Author contribution FR contributed to the manuscript to concept the study design, literature search, data analysis, data interpretation, and article drafting. ER contributed to article drafting, data analysis and interpretation, and article drafting. DF contributed to data analysis and interpretation. OC and SC contributed to data interpretation and manuscript critical revisions. All authors read and approved the final version of the manuscript.

Funding Open access funding provided by Università degli Studi di Milano within the CRUI-CARE Agreement. This research did not receive any specific grant from funding agencies in the public, commercial, or not-for-profit sectors.

\section{Declarations}

Conflict of interest All authors certify that they have no affiliations with or involvement in any organization or entity with any financial interest or non-financial interest in the subject matter or materials discussed in this manuscript.

Research involving human participants and/or animals This study was conducted in conformity to the principles declared to the National Commission for Data Protection and Liberties (CNIL: 2210699) and in accordance with the ethical principles described in the Declaration of Helsinki.

Informed consent All patients or the next kind person signed an informed consent.

Open Access This article is licensed under a Creative Commons Attribution 4.0 International License, which permits use, sharing, adaptation, distribution and reproduction in any medium or format, as long as you give appropriate credit to the original author(s) and the source, provide a link to the Creative Commons licence, and indicate if changes were made. The images or other third party material in this article are included in the article's Creative Commons licence, unless indicated otherwise in a credit line to the material. If material is not included in the article's Creative Commons licence and your intended use is not permitted by statutory regulation or exceeds the permitted use, you will need to obtain permission directly from the copyright holder. To view a copy of this licence, visit http://creativecommons.org/licenses/by/4.0/. 


\section{References}

1. Ashraf I, Hur S, Shafiq M, Park Y (2019) Catastrophic factors involved in road accidents: Underlying causes and descriptive analysis. PLoS One 14(10):e0223473

2. WHO (2015) Global Status Report on Road Safety 2015. World Health Organization, WHO, Geneva

3. Movig KLL, Mathijssen MPM, Nagel PHA, Chu WY, Huang C, Liu S et al (2004) Psychoactive substance use and the risk of motor vehicle accidents. Accid Anal Prev 13(1):36-42. https:// doi.org/10.1007/s11121-011-0242-5

4. Gjerde H, Normann PT, Christophersen AS, Samuelsen SO, Mørland J (2011) Alcohol, psychoactive drugs and fatal road traffic accidents in Norway: a case-control study. Accid Anal Prev 43(3):1197-1203. https://doi.org/10.1016/j.aap.2010.12. 034

5. Carmen del Río M, Gómez J, Sancho M, Alvarez FJ (2002) Alcohol, illicit drugs and medicinal drugs in fatally injured drivers in Spain between 1991and 2000. Forensic Sci Int 127(12):63-70. https://doi.org/10.1016/s0379-0738(02)00116-0

6. Larsen L (2004) Methods of multidisciplinary in-depth analyses of road traffic accidents. J Hazard Mater 111(1-3):115-122. https://doi.org/10.1016/j.jhazmat.2004.02.019

7. Engeland A, Skurtveit S, Mørland J (2007) Risk of road traffic accidents associated with the prescription of drugs: a registrybased cohort study. Ann Epidemiol 17(8):597-602. https://doi. org/10.1016/j.annepidem.2007.03.009

8. Al-Abdallat IM, Al Ali R, Hudaib AA, Salameh GAM, Salameh RJM, Idhair AKF (2016) The prevalence of alcohol and psychotropic drugs in fatalities of road-traffic accidents in Jordan during 2008-2014. J Forensic Leg Med 39:130-134. https://doi. org/10.1016/j.jflm.2016.01.018

9. Gjerde H, Strand MC, Mørland JG (2020) Driving under the influence of non-alcohol drugs. Alcohol Drugs Impair Driv 27(2):89-113

10. Wiener SE, Sutijono D, Moon CH, Subramanian RA, Calaycay J, Rushbrook JI et al (2010) Patients with detectable cocaethylene are more likely to require intensive care unit admission after trauma. Am J Emerg Med 28(9):1051-1055. https://doi. org/10.1016/j.ajem.2009.06.014

11. Hadjizacharia P, Green DJ, Plurad D, Chan LS, Inaba K, Shulman I et al (2009) Methamphetamines in trauma: effect on injury patterns and outcome. J Trauma Inj Infect Crit Care 66(3):895-898. https://doi.org/10.1097/TA.0b013e318164d085

12. Cheng V, Inaba K, Johnson M, Byerly S, Jiang Y, Matsushima $\mathrm{K}$ et al (2016) The impact of pre-injury controlled substance use on clinical outcomes after trauma. J Trauma Acute Care Surg 81(5):913-920. https://doi.org/10.1097/TA.0000000000001229

13. Zeckey C, Dannecker S, Hildebrand F, Mommsen P, Scherer $\mathrm{R}$, Probst $\mathrm{C}$ et al (2011) Alcohol and multiple trauma-is there an influence on the outcome? Alcohol Alcohol 45(3):245-251. https://doi.org/10.1016/j.alcohol.2010.08.004

14. Demetriades D, Gkiokas G, Velmahos GC, Brown C, Murray J, Noguchi T (2004) Alcohol and illicit drugs in traumatic deaths: prevalence and association with type and severity of injuries. $\mathrm{J}$ Am Coll Surg 199(5):687-692. https://doi.org/10.1016/j.jamco 1lsurg.2004.07.017

15. Cherpitel CJ (2007) Alcohol and injuries: a review of international emergency room studies since 1995. Drug Alcohol Rev 26(2):201-214. https://doi.org/10.1080/09595230601146686

16. Stübig T, Petri M, Zeckey C, Brand S, Müller C, Otte D et al (2012) Alcohol intoxication in road traffic accidents leads to higher impact speed difference, higher ISS and MAIS, and higher preclinical mortality. Alcohol 46(7):681-686. https:// doi.org/10.1016/j.alcohol.2012.07.002
17. Phillips DP, Brewer KM (2011) The relationship between serious injury and blood alcohol concentration (BAC) in fatal motor vehicle accidents: $\mathrm{BAC}=0.01 \%$ is associated with significantly more dangerous accidents than $\mathrm{BAC}=0.00 \%$. Addiction 106(9):1614 1622. https://doi.org/10.1111/j.1360-0443.2011.03472.x

18. Walsh JM, Verstraete AG, Huestis MA, Mørland J (2008) Guidelines for research on drugged driving. Addiction 103(8):12581268. https://doi.org/10.1111/j.1360-0443.2008.02277.x

19. Kelly E, Darke S, Ross J (2004) A review of drug use and driving: epidemiology, impairment, risk factors and risk perceptions. Drug Alcohol Rev 23(3):319-344. https://doi.org/10.1080/0959523041 2331289482

20. Brubacher JR, Chan H, Purssell E, Benjamin J, Tuyp BJ, Ting DK, Mehrnoush V (2017) Minor injury crashes: prevalence of driverrelated risk factors and outcome. J Emerg Med 52(5):632-638. https://doi.org/10.1016/j.jemermed.2017.01.044

21. Afshar M, Netzer G, Salisbury-Afshar E, Murthi S, Smith GS (2016) Injured patients with very high blood alcohol concentrations. Injury 47(1):83-88. https://doi.org/10.1016/j.injury.2015. 10.063

22. Vitale S, Van De Mheen D (2006) Illicit drug use and injuries: a review of emergency room studies. Drug Alcohol Depend 82(1):1-9. https://doi.org/10.1016/j.drugalcdep.2005.08.017

23. Cherpitel CJ, Ye Y, Bond J, Rehm J, Poznyak V, Macdonald S et al (2005) Multi-level analysis of alcohol-related injury among emergency department patients: a cross-national study. Addiction 100(12):1840-1850. https://doi.org/10.1111/j.1360-0443.2005. 01257.x

24. Walsh JM, Flegel R, Atkins R, Cangianelli LA, Cooper C, Welsh $C$ et al (2005) Drug and alcohol use among drivers admitted to a Level-1 trauma center. Accid Anal Prev 37(5):894-901. https:// doi.org/10.1016/j.aap.2005.04.013

25. Gómez-Talegón T, Fierro I, González-Luque JC, Colás M, LópezRivadulla M, Álvarez FJ (2012) Prevalence of psychoactive substances, alcohol, illicit drugs, and medicines, in Spanish drivers: a roadside study. Forensic Sci Int 223(1-3):106-113. https://doi. org/10.1016/j.forsciint.2012.08.012

26. Degenhardt L, O'Loughlin C, Swift W, Romaniuk H, Carlin J, Coffey $\mathrm{C}$ et al (2013) The persistence of adolescent binge drinking into adulthood: findings from a 15 -year prospective cohort study. BMJ Open 3(8):e003015. https://doi.org/10.1136/bmjop en-2013-003015

27. Xuan Z, Blanchette JG, Nelson TF, Heeren TC, Nguyen TH, Naimi TS et al (2015) Alcohol policies and impaired driving in the United States: effects of driving- vs. drinking-oriented policies. Int J Alcohol Drug Res 4(2):119-130. https://doi.org/10.7895/ ijadr.v4i2.205

28. Yurasek AM, Aston ER, Metrik J (2017) Co-use of alcohol and cannabis: a review. Curr Addict Rep 4(2):184-193. https://doi. org/10.1007/s40429-017-0149-8

29. Harris DS, Everhart ET, Mendelson J, Jones RT (2003) The pharmacology of cocaethylene in humans following cocaine and ethanol administration. Drug Alcohol Depend 72(2):169-182. https:// doi.org/10.1016/s0376-8716(03)00200-x

30. McCance EF, Price LH, Kosten TR, Jatlow PI (1995) Cocaethylene: pharmacology, physiology and behavioral effects in humans. J Pharmacol Exp Ther 274(1):215-223

31. Mura P, Kintz P, Ludes B, Martin-Dupont S, Vincent F, Kaddour A et al (2003) Comparison of the prevalence of alcohol, cannabis and other drugs between 900 injured drivers and 900 control subjects: results of a French collaborative study. Forensic Sci Int 133(1-2):79-85. https://doi.org/10.1016/s0379-0738(03)00052-5

32. Drummer OH, Gerostamoulos J, Batziris H, Chu M, Caplehorn JRM, Robertson MD et al (2003) The incidence of drugs in drivers killed in Australian road traffic crashes. Forensic Sci Int 134(23):154-162. https://doi.org/10.1016/s0379-0738(03)00134-8 
33. WHO (2018) Global Status Report on Road Safety 2018 World Health Organization, WHO, Geneva

34. Meyer J (2013) 3,4-methylenedioxymethamphetamine (MDMA): current perspectives. Subst Abus Rehabil 21(4):83-99. https://doi. org/10.2147/SAR.S37258
Publisher's Note Springer Nature remains neutral with regard to jurisdictional claims in published maps and institutional affiliations. 